$1-1-1965$

\title{
Design and usage of a Cs137 gamma irradiator for breeding and physiological studies [by] Homer Patrick, R.E. Emerson and H.M. Hyre.
}

Homer Patrick

R.E. Emersen

H. M. Hyre

Follow this and additional works at: https://researchrepository.wvu.edu/ wv_agricultural_and_forestry_experiment_station_bulletins

\section{Digital Commons Citation}

Patrick, Homer; Emersen, R. E.; and Hyre, H. M., "Design and usage of a Cs137 gamma irradiator for breeding and physiological studies [by] Homer Patrick, R.E. Emerson and H.M. Hyre." (1965). West Virginia Agricultural and Forestry Experiment Station Bulletins. 518T.

https://researchrepository.wvu.edu/wv_agricultural_and_forestry_experiment_station_bulletins/662 


\section{Digitized by the Internet Archive in 2010 with funding from \\ Lyrasis Members and Sloan Foundation}


BULLETIN 518T DECEMBER 1965

\title{
DESIGN AND USAGE OF A
} $\mathrm{Cs}^{137}$ GAMMA IRRADIATOR FOR BREEDING AND PHYSIOLOGICAL STUDIES

\section{AG-ENG LIBRARY WEST VIRGINIA UNIVERSITY}

\author{
WEST VIRGINIA UNIVERSITY \\ AGRICULTURAL EXPERIMENT STATION
}




\section{THE AUTHORS}

The authors of Design and L'sage of a Cs= Gamma Irradiator for Breeding and Physiological Studies are Homer Patrick, Agricultural Biochemist; R. E. Emerson. Associate Agricultural Engineer: and H. II. Hyre, Associate Poultry Geneticist.

West V'trgivita Livitersity

Agrictltural Experument Station

Coliege of Agrictittre Aid Forestry

A. H. Varlaidisgham, Director

Morgantow: 


\section{Design and Usage of a Cs ${ }^{17}$ Gamma Irradiator For Breeding and Physiological Studies}

\section{Introduction}

Although new species or forms rarely occur, scientists know that individuals can appear within a specie which have different characteristics. Although the reason or cause of these changes have not been fully determined, some scientists believe that they are due to cosmic radiation. This belief encouraged investigators to use $\mathrm{X}$-rays and gamma rays experimentally. This has resulted in the production of genetic changes in both animals and plants.

Several gamma irradiators containing Cobalt ${ }^{50}$ $\left(\mathrm{Co}^{* 0}\right)$ are in use in the United States. Some are point sources, such as those used at Brookhaven National Laboratory or at Blandy Research Farm in Virginia, or the tube-type holder which has $\mathrm{Co}^{{ }^{6}}$ in tubes held in a position so that they surround the object to be irradiated. This type of arrangement is used at the Universities of Georgia, Florida, and Tennessee. Although it allows high levels of irradiation, the isodose curves are not true circles since there are many small sources located at different distances from the object being irradiated.

A gamma irradiation facility for poultry research should provide a dose-rate high enough for sperm irradiation within the time sperm physiologists are able to maintain the sperm in viable condition; however, the dose-rate should be low enough for use in whole body irradiation in living animal studies. If the doserate is high (over $40,000 \mathrm{r} / \mathrm{hr}$.), the error brought about because of the time required to raise and lower the source when only a few roentgens are used will be great, and if too low $(50-100 \mathrm{r} / \mathrm{hr}$. $)$, the increased mortality or decreased viability of sperm brought about by holding it for the longer period of time required to obtain enough irradiation as recommended for genetic studies will be excessive because poultry sperm does not remain viable for long periods of time.

The gamma rays emitted by the source should be strong enough to effectively penetrate the samples being irradiated, but not so strong as to hinder insulation (shielding) to any great degree.
The radionuclide should be available at a reasonable cost and should have a long enough radiochemical half-life so that the decay rate will be of such an order as to not interfere with the irradiation program per season. Also, the radionuclide unit should be easy to fabricate so that a uniform doserate can be obtained and leakage controlled. Some radioactive metals pass through the holding equipment (molecular channeling) into the water bath much easier than others and hence require special fabrication methods.

A gamma irradiator is defined as a radionuclide device which emits gamma rays. These rays differ from those emitted by an X-ray facility. X-rays are extra nuclear rays given off when the electrons in the shells are disturbed, whereas gamma rays are intranuclear electromagnetic radiations (photons) which arise from nuclear decay and are shorter in length than X-rays. Some investigators indicate that X-rays and gamma rays are identical except for origin; however, they differ in length and strength and in penetrating power.

When gamma rays penetrate matter, they lose their energy by excitation and ionization of the molecules they contact. Gamma rays interact with matter by a variety of processes such as photodisintegration, Bragg's scattering, formation of isometric nuclear levels, photoelectric effect, the Compton effect, and pair production (electron and position production).

There are two possible explanations for the effect of radiation on living tissue or cells. One is the direct inactivation of some essential component of the cell by ionization (a direct hit on an enzyme system, DNA, etc.). The other possibility would be indirect inactivation by an intermediate which is produced by radiations and then reacts with an essential compound. The water molecule has been considered the choice for energy absorption in which it has been estimated that the free radicals $\mathrm{H}^{+}$and $\mathrm{OH}^{-}$are formed within $10^{-12}$ seconds after the passage of a particle or 
photon-induced electron through an aqueous medium. Within a microsecond these radicals have either recombined, combined with identical radicals, or reacted with solutes in the system.

$$
\begin{array}{ll}
\mathrm{H}_{2} \mathrm{O}^{+} & \mathrm{H}^{+}+\mathrm{OH} \\
\mathrm{H}_{2} \mathrm{O}^{-} & \mathrm{H}+\mathrm{OH}^{-} \\
\mathrm{OH}+\mathrm{OH} & \mathrm{H}_{2} \mathrm{O}_{2}
\end{array}
$$

The water molecule loses an electron which changes into a positive water ion. The electron is immediately taken up by another molecule of water to give a negative water ion. The hydroxyl radicals, $\mathrm{OH}$, have a strong oxidizing action and attack organic matter. The unconsumed hydroxyl radicals combine in pairs to form $\mathrm{H}=\mathrm{O}$. The short-lived oxidizing radical, $\mathrm{HO}_{2}$, is also formed.

The influence of gamma irradiation on a biochemical structure could be a chemical change which results in death of the animal because of improper physiological function, or the change could be in the DNA structure of the reproductive or somatic cells. The change in the DNA of the reproductive cells could cause a genetic variation, whereas changes in somatic cells could result in physiological and biochemical variations that would not influence inheritance.

Gamma Ray Energy Absorption

Molecules Chemical Changed

Somatic Cells

$\downarrow$

Biochemical Lesions

$\downarrow$

Physiological Changes

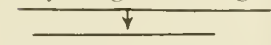

Deatlı Recovery

Some investigators use $\mathrm{Co}^{\text {m }}$ in irradiators because it has greater penetrating power; others prefer Cesium which has less penetrating power. A summary of the radiochemical properties of $\mathrm{Cs}^{137}$ and $\mathrm{Co}^{\infty 0}$ follows:

Comparative Radiochemistry of $\mathrm{Cs}^{135}$ and $\mathrm{Co}^{20}$

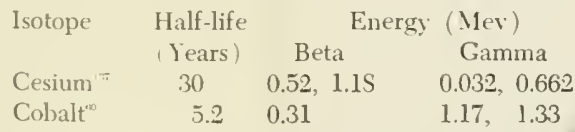

$\mathrm{Cs}^{13}$ is a fission product resulting from the fission of uranium, and $\mathrm{Co}^{\infty}$ is produced by neutron activation $\mathrm{Co}^{\mathrm{s}}\left(\right.$ n.y, $\mathrm{Co}^{m}$.
The decay scheme of $\mathrm{Co}^{\text {so }}$ is as follows:

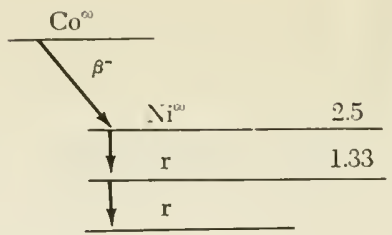

Stable $\mathrm{Ni}^{\infty}$

$\mathrm{CS}^{135}$ is used in the West Virginia University Agricultural Experiment Station Irradiator. The following decay scheme of $\mathrm{Cs}^{135}$ indicates how the gamma ray is produced.

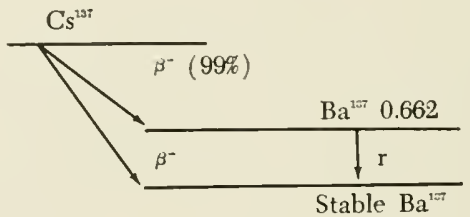

\section{Decay Scheme of Cesium ${ }^{107}$}

The decay scheme of $\mathrm{Cs}^{137}$ show's that the gamma ray is actually produced when the daughter, Barium ${ }^{137}$, decays into stable Barium. The gamma spectra (Figure 1) indicates that the strongest ray produced is $0.662 \mathrm{Mev}$, with a lesser one of $.032 \mathrm{Mev}$. Also, a 0.52 - and a 1.1S-11ev beta particle is produced. $\mathrm{Cs}^{35}$ is an ideal source to use because it has a long radio half-life ( 30 years) and produces a $0.662-\mathrm{Mev}$ gamma ray which is strong enough to penetrate through eggs, tubes of semen, and small animals such as mice, rats and chicks, yet weak enough to allow shielding with reasonable ease.

\section{Design of the Gamma Irradiator}

The West Virginia University Agricultural Experiment Station gamma irradiator contains 300 curies of $\mathrm{Cs}^{15}$ and is designed so that many dose-rates can be obtained $(36,000 \mathrm{r} / \mathrm{hr}$. to $2.5 \mathrm{r}$ hr. $)$. Table 1 indicates the $r$ hr. along with the holders and tables available.

The irradiator assembly consists of three main parts--the building, the well, and the irradiation tables. The building is of filled concrete block, with reinforced concrete roof and floor slabs, as shown in Figure 2. The well is a 12-inch diameter hole extending 12 feet below the floor level of the building and 

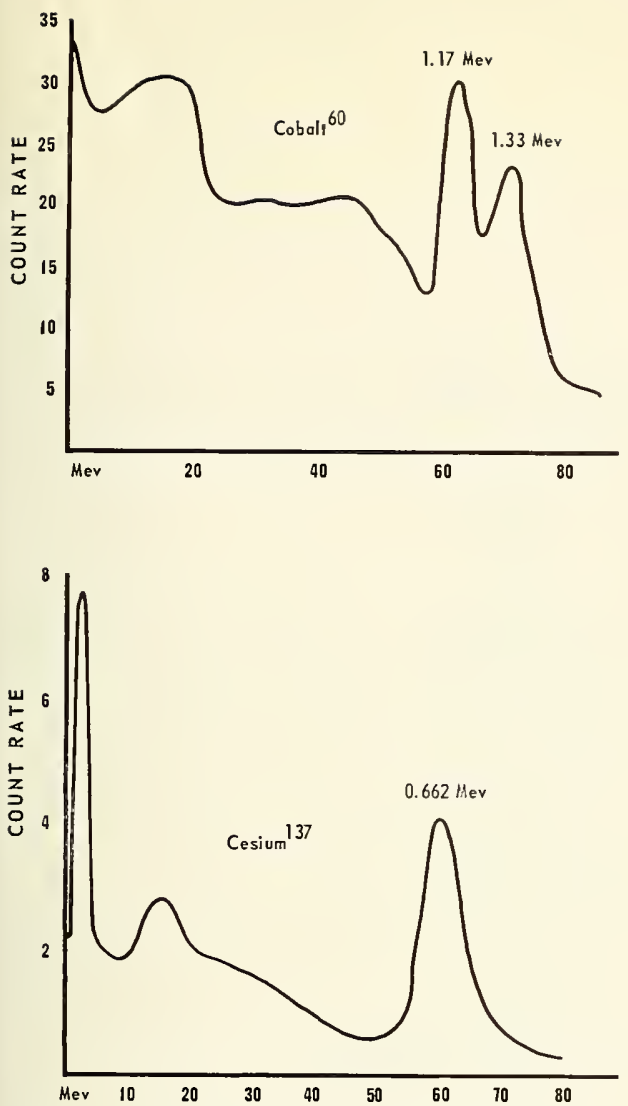

Figure 1. Gamma Spectra of Cobalt ${ }^{\circ 0}$ and Cesium ${ }^{137}$.

cased with aluminum pipe. To provide for loading of the irradiator, a 4 -inch diameter tube is located directly above the well and extends through the ceiling or roof to ground level. Within the well is a 2 -inch diameter aluminum tube which acts as a guide for the capsules containing the irradiation source. The well and its construction details are shown in Figures 2 and 4. The irradiation tables are of three different types and are shown in Figures 5, 6, and 7. The two smaller tables are held in position by clamping them directly to the aluminum well casing, while the third rests on legs and is centered over the well.

This irradiator is housed in a cellar-type reinforced concrete and filled cement block building (Figure 2). The 6-inch reinforced concrete roof is covered with soil. The structure is electrically heated and all metal parts (except electrical fixtures) of the irradiator are constructed of aluminum or stainless steel.

The $\mathrm{Cs}^{157}$ source is enclosed in a 9 -inch aluminum structure resembling a rolling pin (Figure 3 ). The source ( 300 curies of $\mathrm{Cs}^{137}$ ) is sealed in a stainless steel capsule which was designed and constructed by the Oak Ridge National Laboratory as shown in Table 2 (ORNL-LR-DWG 2339A). The capsule containing the cesium source is located midway in the aluminum "rolling pin" so that the unit could be installed with either end in the up or down position. This rolling pin design was used because it could be gripped easily during loading, and the ball-type end allowed the usage of a simple gripper to connect with the stainless steel cable used for raising or lowering. The rolling pin functions up and down in an aluminum type (pipe) with a micro-switch pin indicator-andstopper to signal the position of the source as shown in Figure 4. The $\mathrm{Cs}^{737}$ unit is placed into the 1 -foot diameter aluminum well by way of the irradiator loading tube in the roof. This reduces loading time and provides for greater protection during loading.

The specimen to be irradiated is placed in the holders as shown in Figures 5 and 6 or placed on the tables as shown in Figures 7 and 8. The dose-rates of these holders or tables are presented in Table 1. The holders and tables provide a wide range of dose-rates for irradiation studies. Figure 8 shows a table which provides eight levels of irradiation per hour and is so designed that all eight tables can be operated at one setting. The electric motors used in all the tables or holders are gear-reduction motors.

This gamma irradiator is, for all practical purposes, a point source; hence, the isodose curves are perfect circles.

Table 1

Irradiotion Rates and Holders or Tables

\begin{tabular}{|c|c|c|c|}
\hline $\begin{array}{c}\text { No. Holders } \\
\text { or Tables }\end{array}$ & \begin{tabular}{|c|} 
Shown in \\
Figure
\end{tabular} & $\begin{array}{l}\text { Size Holder } \\
\text { or Table }\end{array}$ & $\mathrm{r} / \mathrm{hr}$. \\
\hline $\begin{array}{l}8 \text { Holders }(14)^{\circ} \\
12 \text { Holders }(7)^{\circ} \\
18 \text { Tables }(1)^{\circ} \\
8 \text { Tables }(3)^{\circ}\end{array}$ & $\begin{array}{l}5 \\
6\end{array}$ & $\begin{array}{l}8 \text { test tubes } \\
3^{\prime \prime} \text { diameter } \\
12 \text { test tubes } \\
11 \text { '" diameter } \\
8^{\prime \prime} \text { tables } \\
6-8 \text { rats or chicks } \\
\text { per table } \\
8^{\prime \prime} \text { tables } \\
6-8 \text { rats or chicks } \\
\text { (one at each level } \\
\text { as shown) }\end{array}$ & $\begin{array}{cc}800, & 700 \\
600, & 400 \\
200, & 100 \\
50, & 25\end{array}$ \\
\hline
\end{tabular}

${ }^{\circ}$ Revolutions per minute of each table or holder. 


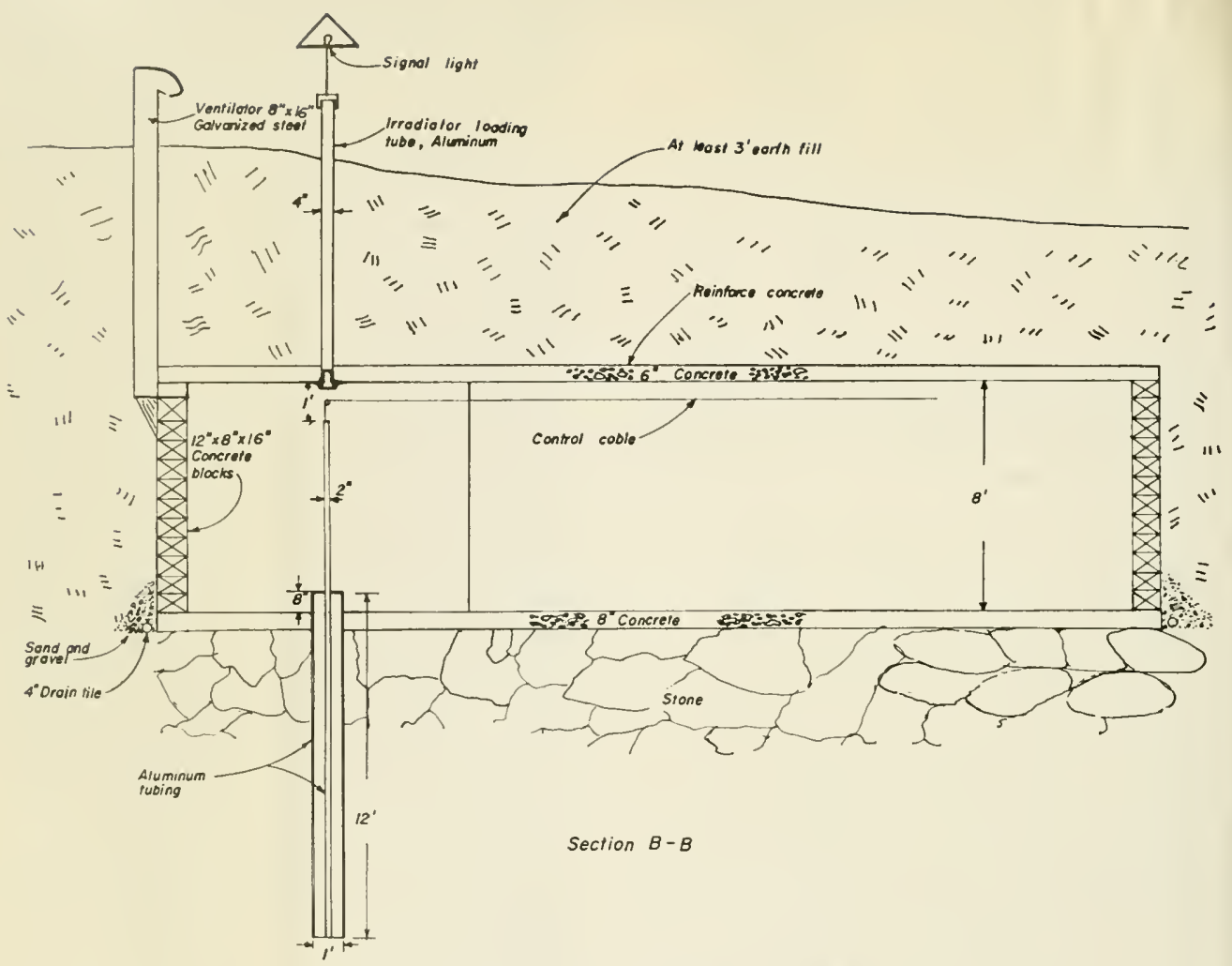

Figure 2. Gamma Irradiator Laboratory Building.

Any irradiation program requires a thorough understanding of the strength of the irradiator and also some biological index to base or use as a standard. The decrease in spleen weight of chicks 21 days old or 200-gram rats, the serum phosphatase level in chicks, or the amount of irradiation required to reduce fertility 50 per cent in breeding hens inseminated with irradiated sperm are indexes used at the West Yirginia Station (Table 2). The common expression for irradiation studies are LD 50 for fertility, LD 50 for spleen weight, and LD 50 for phosphatase-which means the amount of irradiation required to reduce fertility, spleen weight, or phosphatase 50 per cent.

The data in Table 2 on the influence of gamma irradiation on spleen weight, serum alkaline phosphatase and $\mathrm{Se}^{\mathrm{T}}$ retention of cockerels three weeks of age demonstrate that this irradiator which allows many groups of aninals and different dose rates can produce more usable data than most irradiators. Also, the energy level is such that a high level of irradiation can be used in animal work without causing high early mortality. The trends in the present data are similar to reported results but uniformity is improved.

This gamma irradiator offers several advantages over some existing units:

1. The $\mathrm{Cs}^{137}$ has a half-life of more than 30 years as compared to $\mathrm{Co}^{\text {sin }}$ with a half-life of 5.27 years. The long half-life of $\mathrm{Cs}^{137}$ allows seasonal studies to be made without large changes in irradiation rates being made. Also, the need for replacement of the radioactivity is reduced greatly.

2. The gamma ray of $0.662 \mathrm{Mev}$ of the $\mathrm{Cs}^{10 \pi} \mathrm{ir}-$ radiation as compared to $1.33 \mathrm{Mev}$ of $\mathrm{Co}^{\text {ro }}$ gives the $\mathrm{Cs}^{13 \pi}$ unit enough energy to penetrate tissues, but it is not difficult to insulate. 


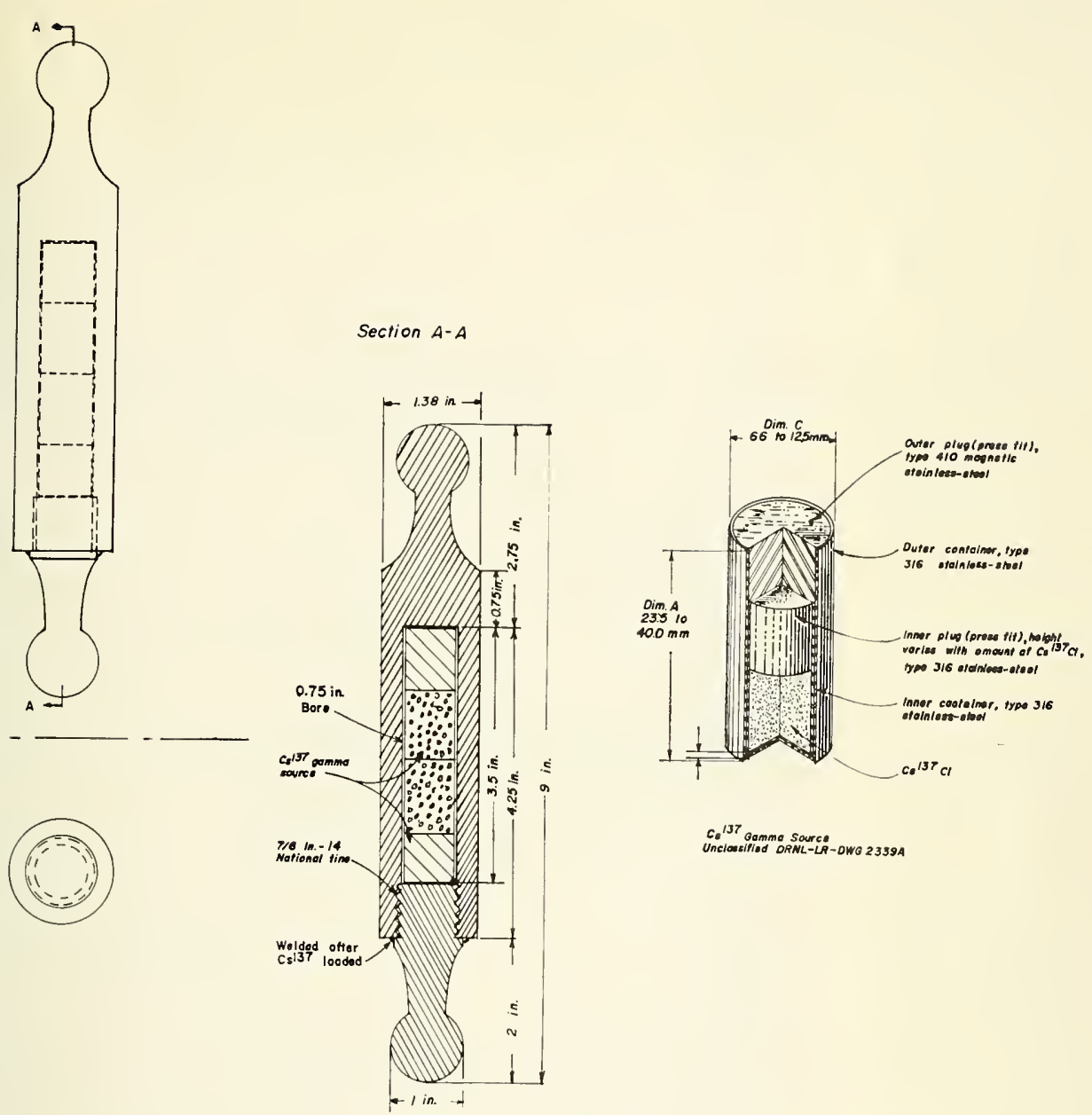

Figure 3. $\mathrm{Cs}^{\natural \hbar}$ Capsule.

This irradiator allows many levels of irradiao be obtained at one setting, yet gives uniform e to each sample or specimen.

- This irradiator is a point source; therefore, a $\mathrm{m}$ dose rate can be obtained.
5. The source holder is so designed that leakage is almost not possible and handling is very easy.

6. The underground construction allows uniform temperature, insulation to be maintained with ease, as well as freedom from noises. This is very important in handling animals in strange quarters. 


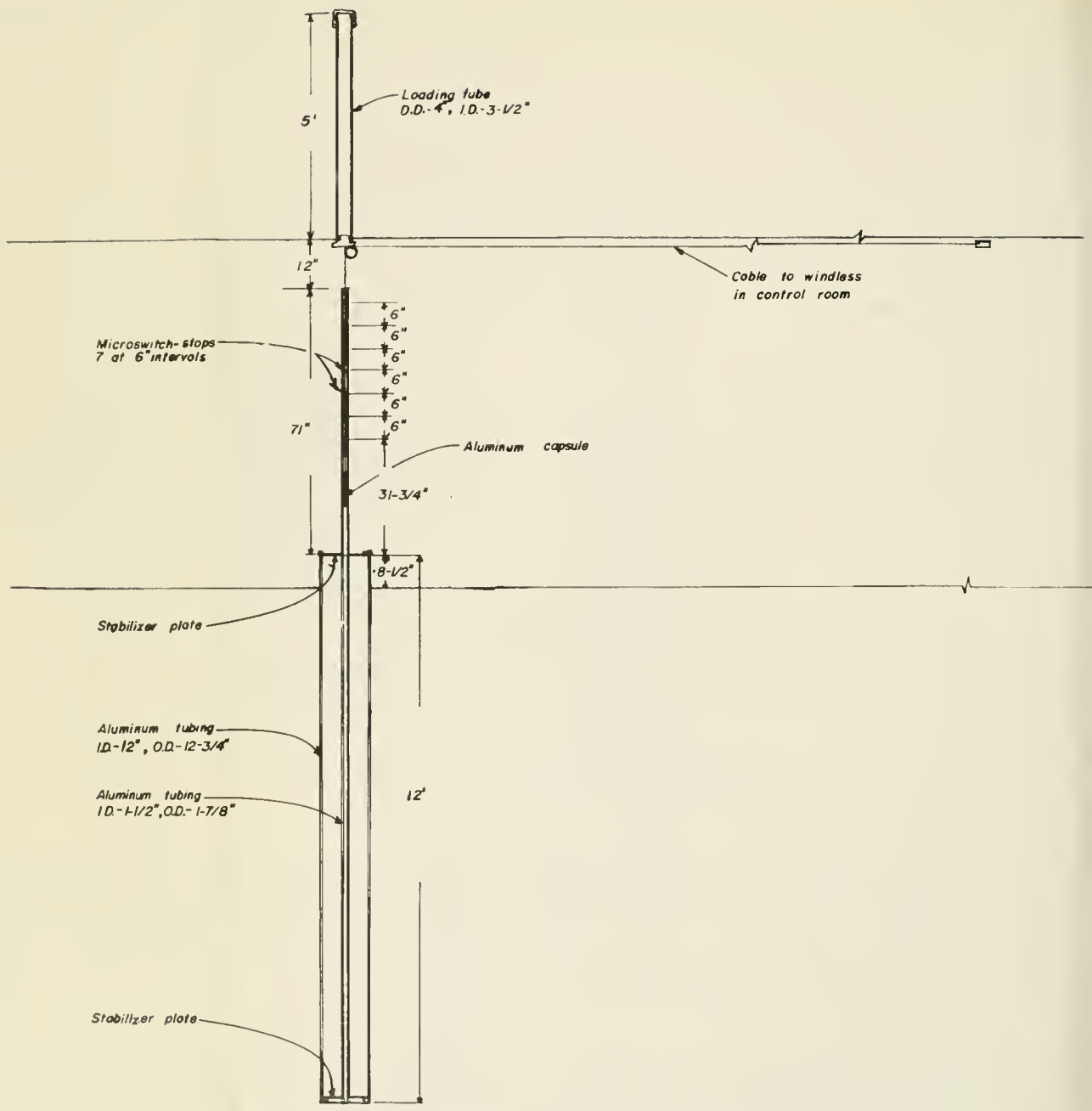

Figure 4. $\mathrm{Cs}^{137}$ Well and Microsuitch Positions.

8 
Table 2

Influence of Gamma Irradiation, Spleen Weight, Serum Alkaline Phosphatase and $\mathrm{Se}^{75}$ Retention in 3-week-old Cockerels

\begin{tabular}{|c|c|c|c|c|c|c|c|c|c|}
\hline $\begin{array}{l}\text { Total Dose ( } r \text { ) } \\
\text { of Gamma Irradiation }\end{array}$ & 1600 & 1400 & 1200 & 800 & 400 & 200 & 100 & 50 & 0 \\
\hline Dose rate $r / h r$ & 800 & 700 & 600 & 400 & 200 & 100 & 50 & 25 & 0 \\
\hline \multicolumn{10}{|c|}{$\begin{array}{l}\text { White Leghorn Cockerels } \\
\text { (21 days old) } \\
\text { Spleen }^{\circ}\end{array}$} \\
\hline Avg. Wt. (gms) & .038 & .036 & .041 & .038 & .049 & .066 & .071 & .092 & 11 \\
\hline $\begin{array}{l}\text { Se }^{i 50} \text { content } \\
\text { Alkaline }\end{array}$ & 6.45 & 7.55 & 8.25 & 12.6 & 16.1 & 17.2 & 28.1 & 27.8 & 27.9 \\
\hline Phosphatase & 73 & 138 & 168 & 138 & 168 & 182 & 196 & 218 & 240 \\
\hline
\end{tabular}

'Results obtained 24 hours post irradiation. Phosphatase expressed as Sigma Units of alkaline phosphatase, per ml. of blood serum. $\mathrm{Se}^{75}$ expressed as per cent of a standard containing a known amount of $\mathrm{Se}^{75}$.

Table 3

The LD $\mathbf{5 0}$ of Irradiated Sperm*

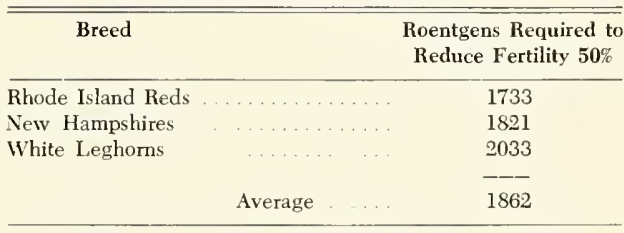

'The semen was diluted 50-50 with a phosphate ringers solution and subjected to different levels of irradiation using the hold which provided $3,600 \mathrm{r} / \mathrm{hr}$. The hens were artificially inseminated with the semen after treatment and fertility were determined. The average level of irradiation required to reduce fertility 50 per cent was found to be $1862 \mathrm{r}$.
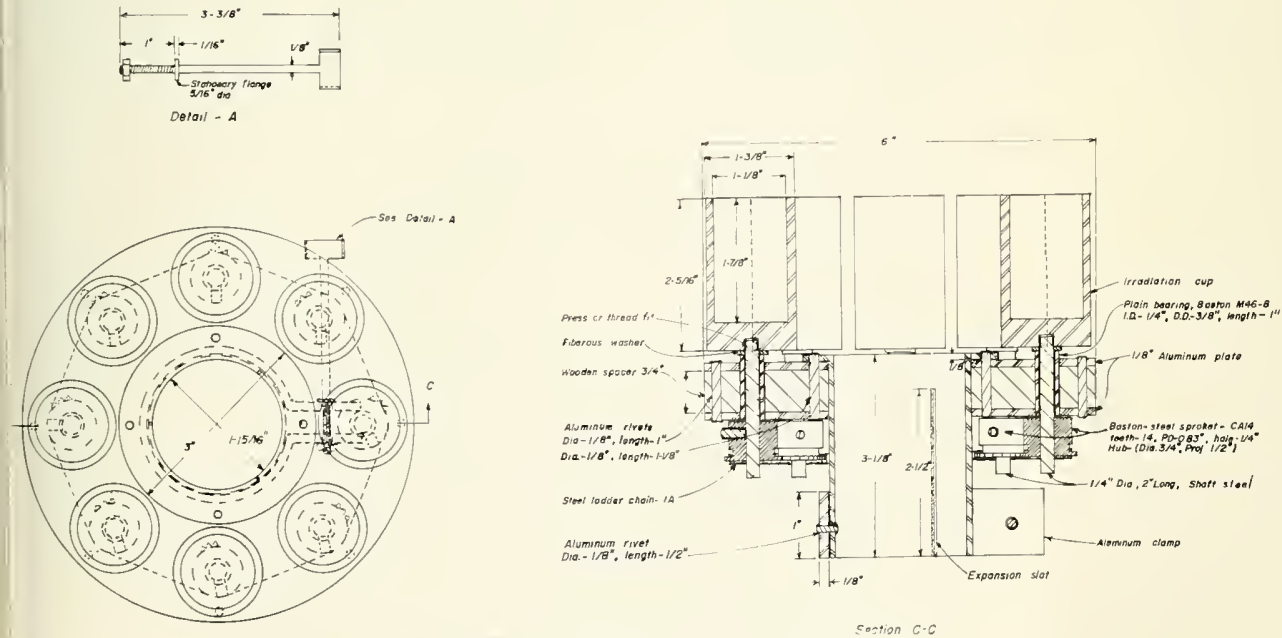

Figure 5. High Level $(36,000 \mathrm{r} / \mathrm{hr})$ Holders. 


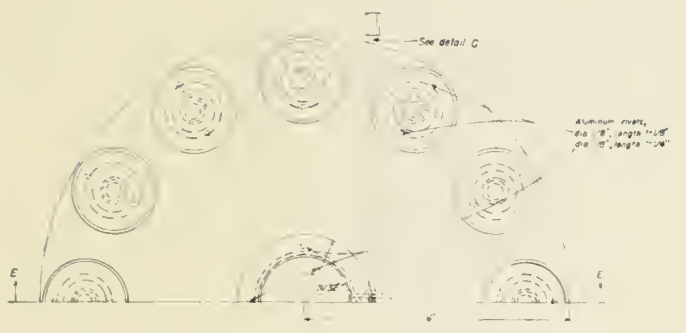

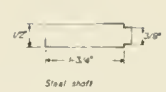

De's $B$

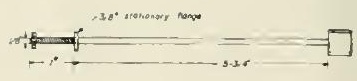

Detait $C$

Holf of Top View
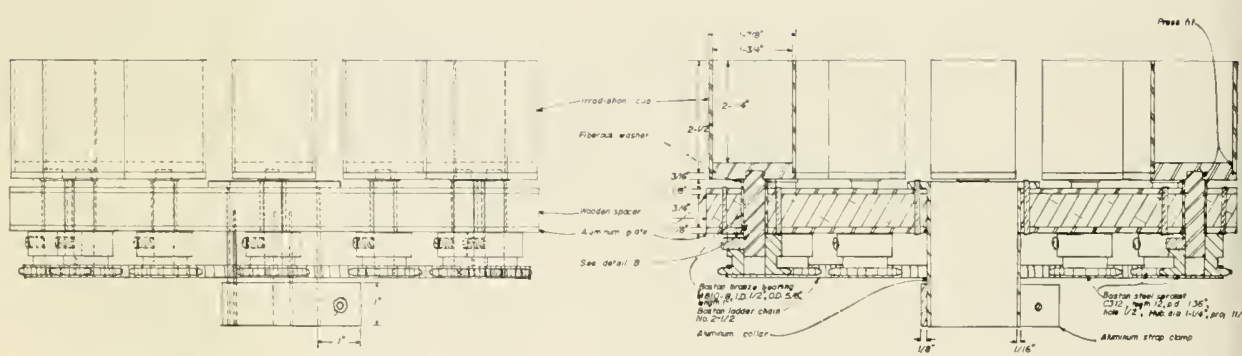

Section $E-E$

Figure 6. IIolding Table $(3,600 \mathrm{r} h \mathrm{hr}$.). 

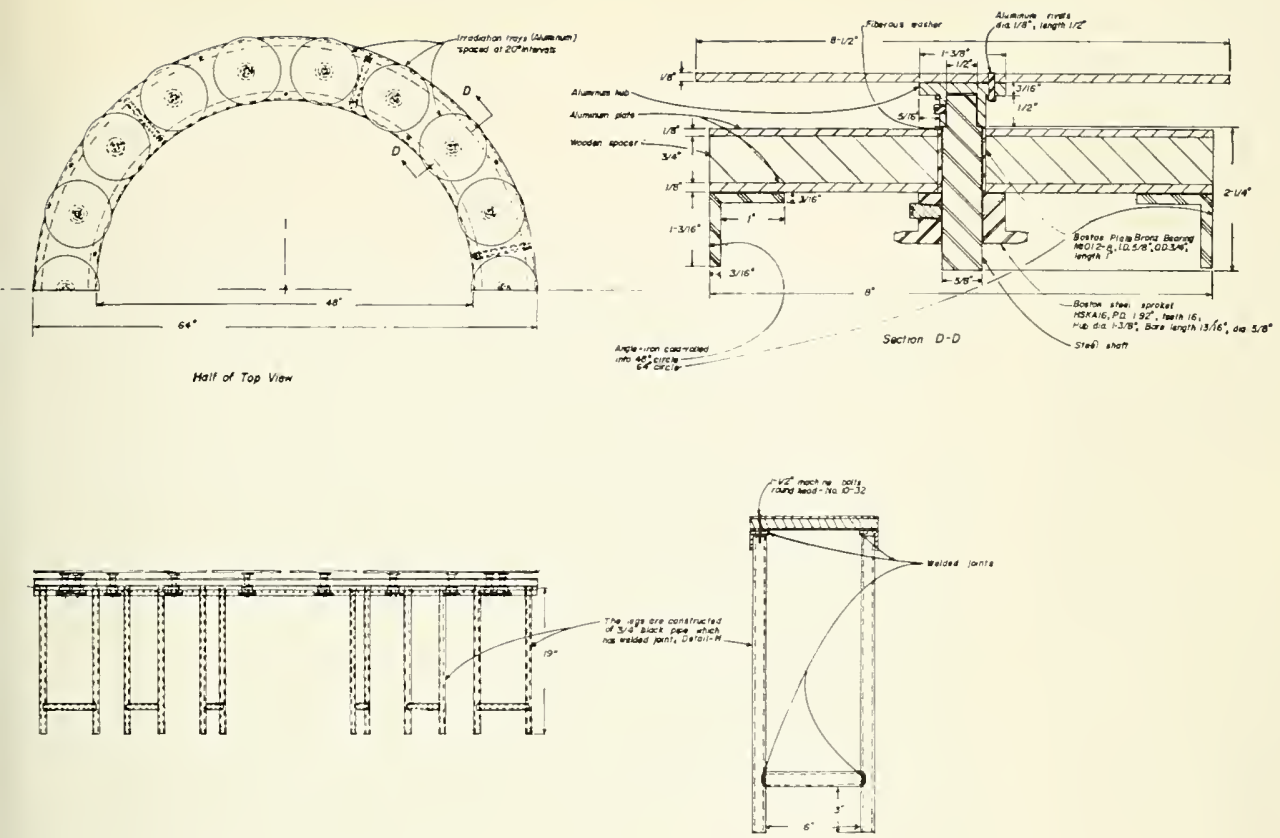

Detoil-H

Figure 7. Irradiation Holding Units (180 r/hr.).

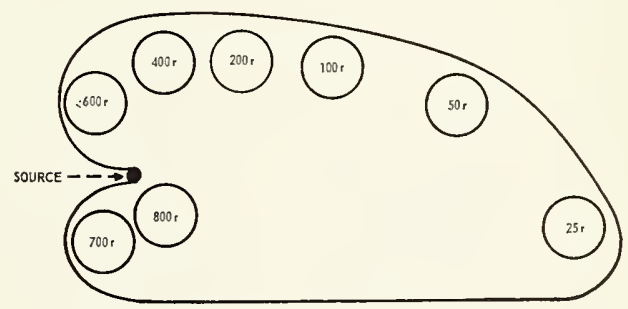

Figure 8. Multiple Dose-Rate Table Top. 



$$
\text { . }
$$


$1+1$

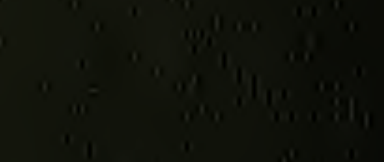

ing
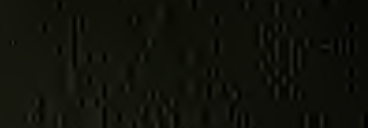